\title{
The Effect of Intra-Articular Injection of Hyaluronic Acid on the Degenerative Pathology of the Temporo- Mandibular Joint
}

\author{
Batifol $\mathrm{D}^{1 *}$, Finiels $\mathbf{P}^{2}$ and Jammet $\mathbf{P}^{1}$ \\ ${ }^{1}$ Maxillofacial Surgery Department, University Hospital Gui de Chauliac, Montpellier, France \\ ${ }^{2}$ Orthopedics, Traumatology and Spine Neurosurgery Department Alès General Hospital, Alès, France
}

\begin{abstract}
Introduction: Manducator dysfunction is common in the field of maxillo-facial surgery. Intra-articular injection of hyaluronic acid is beneficial in certain degenerative arthritic conditions leading to improved pain and function. This study investigated 310 patients treated with intra-joint hyaluronic acid for treatment-resistant, degenerative manducator apparatus dysfunction during 2 years from January 2015 to December 2016.
\end{abstract}

Materials and methods: 310 patients presenting with degenerative manducator apparatus dysfunction, according to clinical diagnosis and magnetic resonance imaging, received $1 \mathrm{ml}$ hyaluronic acid in the temporo-mandibular joint. Clinical parameters comprised joint pain, presence of joint noises, maximum buccal opening and patient comfort. Patient follow-up was scheduled pre-injection and 2 and 6 months post-injection.

Results: Descriptive statistical analysis demonstrated improvements in all clinical parameters. These data concur with other published studies confirming the efficacy of hyaluronic acid in reducing the symptoms of joint dysfunction associated with degenerative bone disease.

Discussion: Hyaluronic acid is beneficial for the treatment of arthritic degenerative diseases. Results from this study showed improved clinical symptoms in all 310 patients with manducator apparatus dysfunction over 6 months. Treatment was well-tolerated and may be superior to corticosteroids in improving pain and function. Further methodologically clinical trials are required to confirm the use of intra-joint hyaluronic acid in this field.

\section{Introduction}

Manducatory dysfunction is one of the most frequent reasons for clinical consultation in the field of maxillo-facial surgery. Chronic dysfunction causes degeneration of the temporo-mandibular joints (TMJ), due to a disturbance in the equilibrium of the degenerative and repair processes of fibrous connective tissue, cartilage, bone and the synovial liquid [1].

Many different therapeutic approaches have been proposed to manage this condition, but their efficacy is often variable and controversial. Hyaluronic acid (HA) is a polysaccharide of the glycosaminoglycan family. It can be found in a number of extra-cellular tissues, including synovial liquid and cartilage. It is produced by chondrocytes in the articular discs and the synovialocytes [2]. In patients with arthritis, HA is depolymerised resulting in a reduction of molecular weight and, thus, viscoelasticity. These changes increase the sensitivity of the cartilage to damage. However, treatment using exogenic HA causes stimulation of the synthesis of its endogenous counterpart [2].

The objective of this study was to investigate prospectively a series of patients presenting with manducatory dysfunction which had reached the stage of bone degeneration. Diagnosis was confirmed both clinically and radiologically and patients were then treated with an intra-joint injection of hyaluronic acid.

\section{Materials and methods}

We retrospectively reviewed data for all patients with chronic TMJ dysfunction between January 2015 and December 2016 and included all patients who presented dysfunction of the TMJ, together with clinical and/or radiological signs of degeneration. Patients provided written informed consent prior to participation to the study, which has been first approved by our local ethics committee.

Study inclusion criteria comprised the presence of joint pain associated with restricted buccal opening and/or joint squeaking noises. Magnetic resonance imaging (MRI) scans were conducted on all patients before the first injection and then 2 months post-treatment to analyse the integrity of the disc and bone. Temporo-mandibular bone structure degeneration was investigated through assessment of osteophytes, erosion, sclerosis, irregularity of bone surfaces, condyle deformation and possible signs of disc displacement [3]. Patients were

Correspondence to: Dominique Batifol, Maxillofacial Surgery Department, Hospital Gui de Chauliac, 80 avenue Augustin Fliche, 34295 Montpellier cedex 5, France, E-mail: dominique.batifol@dbmail.com

Key words: arthritis, hyaluronic acid (ha), manducator apparatus, temporomandibular joint

Received: January 06, 2018; Accepted: January 22, 2018; Published: January 26, 2018 
excluded from the study if they have a dysfunction of the manducator apparatus which was specifically of muscular aetiology.

Patients received either a uni- or bilateral temporo-mandibular intra-joint injection of $1 \mathrm{ml}$ HA (Arthrum: LCA Pharmaceutical, Chartres, France). Patients were assessed at time of diagnosis, at HA injection and during 2 follow-up assessments scheduled at 2 and 6 months post-treatment. During each of these visits, clinical parameters comprising joint pain (using a visual analogue scale [VAS]), presence of joint noises using a stethoscope, maximal buccal opening capacity (before and after injection) measured between the free edges of the incisors, and comfort (as rated by the patient during interview) were recorded. All assessments at each visit were performed by the same assessor in order to minimise inter-rater variation.

A maximum buccal opening of $50.7 \pm 7 \mathrm{~mm}$ was considered normal [4]. Pain rated between 0 and 3 was considered 'absent to mild', scores between 4 and 6 were judged as 'moderate', and values between 7 and 10 were considered as 'strong to incapacitating' pain. A 3-point scale was used to assess joint noises whereby 2 indicated 'loud noises', 1 corresponded with 'quiet noises' and 0 was for 'absence of noise'. During the visits an evaluation of patient comfort was recorded through interview and classified using a 3-point scale (2: 'large improvement', 1: 'moderate improvement' and 0 : 'no improvement').

During the first study visit and prior to the HA injection, each patient underwent an examination of the manducator muscles. Those patients who presented with a marked hypertensive muscle component received an injection of botulinum toxin type-A (BoNTA) (BOTOX: Allergan Pharmaceuticals, Westport, Ireland) into the masseter muscles and, where indicated, into the temporal muscles. The doses of BoNTA used ranged from 40 to $70 \mathrm{U}$ for the masseter muscles and from 10 to $25 \mathrm{U}$ for the temporal muscles. BoNTA was given 15 days prior to the injection of HA in order to avoid rejection of HA through high pressure caused by muscular contraction. Such an occurrence had been noted by us on 2 occasions prior to the conduct of this study.

Prior to HA injection, lidocaine $2 \%$ adrenalin local anaesthetic (Laboratoires Aguettant, France) was used for all patients, with the exception of those in which use of this product was contraindicated. Rigorous aseptic techniques were adhered to using iodised povidone (Medical MundiPharma Company, Basel, Switzerland) which was applied over a wide area at least 5 minutes prior to HA injection. The injection site was identified using accurate palpation of the joint. Confirmation that the articular capsule had been penetrated and that HA had entered the articular disc space was confirmed through immediate appearance of molar dysclusion. No specific precautions were imposed on the patient following injection.

\section{Results}

A total of 310 patients were treated: 160 patients presented with a combination of muscular and articular dysfunction and 150 patients had only articular disease. The disease was bilateral in 190 patients and unilateral in 120 patients. Thirty patients had a medical history of bilateral capital condyle fracture and 50 patients had previously undergone temporo-mandibular disc surgery. Two hundred ten patients received an intra-muscular injection of BoNTA 15 days prior to the intra-joint injection of HA due to muscular hypertension, but this was considered unnecessary in 100 patients who presented with weak to normal musculature. The ratio of male to female patients was 1:5 and the mean age was 47.5 years (range $15-80$ years).

\section{Joint pain}

Pre-treatment assessment confirmed that all patients experienced joint pain, with 220 patients experiencing strong pain and 90 patients with moderate pain at the time of diagnosis. Two hundred forty patients presented with all 3 clinical symptoms of pain, including limited buccal opening and joint noises. Forty patients complained of pain and limited buccal opening without associated joint noises, and 30 patients presented with pain and articular noises, but without limited buccal opening.

At the first post-treatment assessment, scheduled at 2 months after HA injection, only 30 patients still complained of strong pain, while 110 patients had moderate pain and 170 reported mild pain. At 6 months post-injection, 50 patients presented with moderate pain and 260 indicated pain levels ranging from mild to no pain (Table 1).

\section{Articular noises}

Articular noises before the injection of HA were rated as loud in 210 patients, quiet in 70 patients and absent in 30 patients. Two months after the injection, 10 patients still had loud noises, 190 had quiet noises and the remaining 110 patients had no articular noise. At 6 months post-injection, no patients had loud noises, 60 had quiet noises and 250 patients had no noises (Table 2).

\section{Maximum buccal opening}

Prior to HA injection, mean buccal opening was $30.1 \mathrm{~mm}$. This increased to a mean of $35.2 \mathrm{~mm}$ after injection $(37 \mathrm{~mm}$ at 2 months postinjection and $40 \mathrm{~mm}$ at 6 months post-injection - Figure 1). However, buccal opening reduced immediately following injection in 30 patients and an improvement was not detected until the first follow up visit. Six months after HA injection, buccal opening had improved in all patients, except ten who developed temporo-mandibular ankylosis despite treatment, one of them had a bilateral capital condyle fracture.

\section{Patient comfort}

Two months after HA injection, 200 patients reported a moderate improvement in their quality of life, 70 patients reported a large improvement and 40 patients indicated no change. At 6 months posttreatment, only ten patients, with a late diagnosis of temporomandibular ankylosis, indicated no improvement, 80 patients reported a moderate improvement, while 220 patients reported a large improvement (Table 3 ).

Table 3. Patient Comfort Level.

\begin{tabular}{|c|c|c|}
\hline Comfort & 2 months post-treatment & 6 months post-treatment \\
\hline 0 (no improvement) & 40 & 10 \\
\hline 1 (moderate improvement) & 200 & 220 \\
\hline 2 (large improvement) & 70 & 80 \\
\hline
\end{tabular}

Table 1. Pain Assessment.

\begin{tabular}{|c|c|c|c|}
\hline VAS Scale & Pre-Treatment & $\begin{array}{c}\text { 2 months } \\
\text { post-treatment }\end{array}$ & $\begin{array}{c}\text { 6 months } \\
\text { post-treatment }\end{array}$ \\
\hline $0-3$ (absent to mild) & 0 & 170 & 260 \\
\hline $4-6$ (moderate) & 90 & 110 & 50 \\
\hline $\begin{array}{c}7-10 \text { (strong to } \\
\text { incapacitating) }\end{array}$ & 220 & 0 & 0 \\
\hline
\end{tabular}

Table 2. Articular Noise.

\begin{tabular}{|c|c|c|c|}
\hline Joint noises & Pre-treatment & $\begin{array}{c}\text { 2 months } \\
\text { post-treatment }\end{array}$ & $\begin{array}{c}\text { 6 months post } \\
\text { treatment }\end{array}$ \\
\hline 0 (absence of noise) & 30 & 110 & 250 \\
\hline 1 (quiet noise) & 70 & 190 & 60 \\
\hline 2 (loud noise) & 210 & 10 & 0 \\
\hline
\end{tabular}




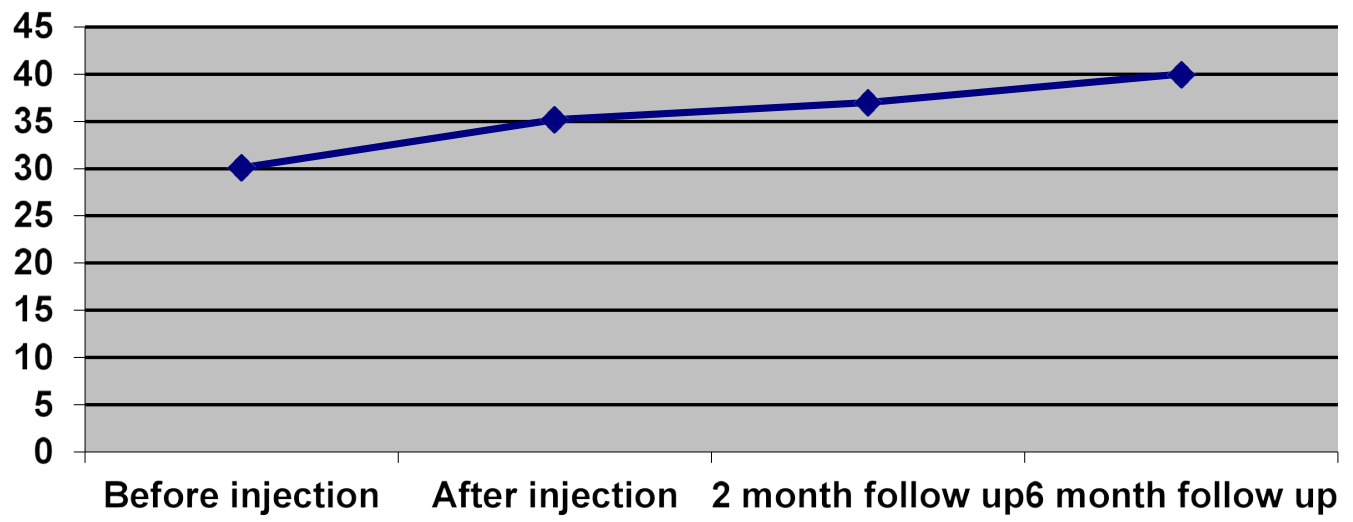

Figure 1. Changes in Buccal Opening over Time.

\section{Radiology}

Radiological investigation revealed signs of arthritis in 230 patients. Eighty patients showed clinical signs without evidence of radiologically visible degenerative lesions. MRI scans showed no change (i.e. neither improvement nor worsening) for all patients.

\section{Discussion}

The potential benefits of HA for the treatment of the temporomandibular joint was hypothesised from its widespread and successful use for the treatment of rheumatoid symptoms of arthritic degenerative disease. In arthritis, the concentration and the molecular weight of HA in the synovial fluid are reduced through dilution, fragmentation and production of low weight HA by the synoviocytes. The intra-articular injection of viscoelastic HA has proven useful in the treatment of certain degenerative arthritic conditions, leading to significant improvement in both pain and function $[5,6]$. In addition, a study in sheep demonstrated the successful action of HA in preventing the progression of temporomandibular arthritis by encouraging the development of joint cartilage and inhibiting the proliferation of fibrous tissue [7].

This study was based upon the hypothesis that intra-joint HA injections may restore the viscosity of the synovial fluid, thus promoting the synthesis of endogenous HA with a higher molecular weight which would therefore be more functional, and as a result improve the mobility and function of the joints, while also providing pain relief. Results showed that there were an improvement of clinical symptoms in all 310 patients over the 6 month follow-up period and therefore indicates the short-term efficacy of HA injections in patients with manducator dysfunction. Six months after HA injection, 260 patients indicated pain levels ranging from mild to no pain, with only 50 patients still suffered moderate pain. Maximum buccal opening was improved in all patients except 10 patients and joint noises were reduced, with only 60 patients still revealing quiet joint noises.

In 30 patients, buccal opening reduced immediately after injection and an improvement was not detected until the first follow-up visit. This may possibly be explained by the pain caused by the injection itself and the particular psychological characteristics of certain patients.

Our results concur with those of other published studies, although these other trials used cycles of 5 HA injections scheduled at weekly intervals and symptom improvement was noted following the second injection $[8,9]$. It is important to note, however, that GuardaNardini, et al. administered HA injections following arthocentesis which, according to our experience, may also be a source of clinical improvement [10].
It is appropriate to compare the use of intra-joint HA to that of intra-joint corticoids $[11,12]$. Corticoids have been the treatment of choice for many years, although their efficacy is questionable since most placebo-controlled trials have only shown a slight, short-term clinical improvement which does not usually exceed one week. The efficacy of HA is either below or equivalent to that of corticoids following treatment administration (i.e. from week 1 to week 3), but this then improves to demonstrate superiority over corticoids by significantly improving pain and function in the long-term [13].

Few adverse effects have been reported in the literature as a result of intra-joint injection of HA. These comprise one case of bone necrosis of the temporal tubercle [14], one case of septic arthritis of the knee [15] and 5 cases of inflammatory granulomatosis of the knee [16]. With respect to this study, treatment was well-tolerated by all patients and there were no reported adverse effects.

\section{Conclusion}

In conclusion, this study demonstrates interesting initial results, but further methodologically rigorous studies comprising large, longterm, prospective, randomised clinical trials in the use of intra-joint HA to treat degenerative temporo-mandibular joint dysfunctions are required to establish the performance of repeat treatment cycles of HA over longer periods of follow-up.

We are aware that treat all temporo-mandibular dysfunction is a subject of very broad investigation and that our results are not specific for a particular disease. Further investigations as a prospective study, seeking results for different groups are mandatory to see if we could find changes according to different panels of pathologies.

\section{References}

1. Chassagne JF, Chassagne S, Fyad JP, Simon E, Gillet P, et al. (2002) Pathologie non traumatique de l'articulation temporomandibulaire. Encycl Méd Chir, Elsevier, Paris, Stomatologie, 46.

2. Guarda-Nardini L, Stifano M, Brombin C, Salmaso L, Manfredini D (2007) A one-year case series of arthrocentesis with hyaluronic acid injections for temporomandibular joint osteoarthritis. Oral Surg Oral Med Oral Pathol Oral Radiol Endod 103: 14-22. [Crossref]

3. Emshoff R, Innerhofer K, Rudisch A, Bertram S (2002) The biological concept of "internal derangement and osteoarthrosis": a diagnostic approach in patients with temporomandibular joint pain? Oral Surg Oral Med Oral Pathol Oral Radiol Endod 93: 39-44. [Crossref]

4. Placko G, Bellot-Samson V, Brunet S, Guyot L, Richard O, et al. (2001) L'ouverture buccale normale dans la population française adulte. Rev de Stomat et Chir Maxillofac 106: $267-271$. 
5. Huskisson EC, Donnelly S (1999) Hyaluronic acid in the treatment of osteoarthritis of the knee. Rheumatology 38: 602-607. [Crossref]

6. Wobig M, Bach G, Beks P, Dickhut A, Runzheimer J, et al. (1999) The role of elastoviscosity in the efficacy of viscosupplementation for osteoarthritis of the knee: a comparison of hylan G-F 20 and a lower-molecular-weight hyaluronan. Clin Ther 21: 1549-1562. [Crossref]

7. Kim CH, Lee BJ, Yoon J, Seo KM, Park JH, et al. (2001) Therapeutic effect of hyaluronic acid on experimental osteoarthrosis of ovine temporomandibular joint. $J$ Vet Med Sci 63: 1083-1089. [Crossref]

8. Fuchs S, Monikes R, Wohlmeiner A, Heyse T (2006) Intra-articular hyaluronic acid compared with corticoid injections for the treatment of rhizarthrosis. Osteoarthritis Cartilage 14: 82-88. [Crossref]

9. Guarda Nardini L, Oliviero F, Ramonda R, Ferronato G (2004) Influence of intra articular injections of sodium hyaluronate on clinical features and synovial fluid nitric oxide levels of temporomandibular osteoarthritis. Reumatismo 56: 272-277. [Crossref]

10. Guarda-Nardini L, Masiero S, Marioni G (2005) Conservative treatment of temporomandibular joint osteoarthrosis: intra-articular injection of sodium hyaluronate. J Oral Rehabil 32: 729-734. [Crossref]
11. Agus B, Weisberg J, Friedman MH (1983) Therapeutic injection of the temporomandibular joint. Oral Surg Oral Med Oral Pathol 55: 553-555. [Crossref]

12. Lida K, Kurita K, Tange K, Yoshida K (1998) Necrosis of the articular tubercle after repeated injections of sodium hyaluronate in temporomandibular joint. A case report Int J Maxillofac Surg 27: 278-279. [Crossref]

13. Maheu E, Guillou GB (1994) Corticothérapie intra-articulaire dans la gonarthrose: une habitude mais pas de preuve. Rev Prescrire 14: 475-477.

14. Lequerre T, Nouvellon M, Kraznowska K, Bruno MC, Vittecoq O, et al. (2002) Septic arthritis due to Actinomyces naeslundii: report of a case. Joint Bone Spine 69: 499-501. [Crossref]

15. Chen AL, Desai P, Adler EM, Di Cesare PE (2002) Granulomatous inflammation after Hylan G-F 20 viscosupplementation of the knee: a report of six cases. J Bone Joint Surg Am 84: 1142-1147. [Crossref]

16. Hepguler S, Akkoc YS, Pehlivan M, Ozturk C, Celebi G, et al. (2002) The efficacy of intra-articular sodium hyaluronate in patients with reducing displaced disc of the temporomandibular joint. J Oral Rehabil 29: 80-86. [Crossref]

Copyright: $(2018$ Batifol D. This is an open-access article distributed under the terms of the Creative Commons Attribution License, which permits unrestricted use, distribution, and reproduction in any medium, provided the original author and source are credited. 